https://orcid.org/0000-0001-6444-2631

\title{
HistóRIa, Direito e Literatura: Uma TRIANGUlaÇão EM Prol do Constitucionalismo
}

\author{
Henriete Karam* \\ Guilherme Gonçalves Alcântara**
}

\begin{abstract}
1 Considerações iniciais: os impasses de uma constituição trintenária. 2 História e literatura. 3 Direito e literatura. 4 O caráter universal da hermenêutica e a posição-limite da literatura. 5 Considerações finais - que posições podem tomar direito-literaturahistória? Referências.
\end{abstract}

\section{RESUMO}

O presente artigo, de viés interdisciplinar, tem como objetivo examinar os modos de incorporação da literatura aos estudos historiográficos do direito, particularmente no que diz respeito à esfera do direito constitucional. Partindo do pressuposto de que história e direito sempre estiveram próximos - embora tal proximidade não seja comumente reconhecida -, defende-se que a interlocução da historiografia do direito com a literatura constitui uma via imprescindível para superar impasses e avançar na construção de uma cultura constitucional adequada à modernidade tardia brasileira. Para tanto, são examinadas, mediante pesquisa bibliográfica, as intersecções entre história e literatura, bem como entre direito e literatura, com ênfase na posição-limite que a literatura ocupa no âmbito da hermenêutica filosófica, marco teórico que viabiliza o diálogo das três disciplinas, possibilitando à triangulação história-direito-literatura contribuir para a renovação da história constitucional e, consequentemente, para a construção de uma cultura constitucional no Brasil. Conclui-se identificando três eixos de estudo a partir da triangulação proposta, os quais se caracterizam: (1) pelo emprego de conceitos e de metodologias oriundas da teoria literária no exame dos textos de história do direito, abordando seu caráter inexoravelmente narrativo; (2) pela proposta de reformulação da metáfora da integridade do direito como romance histórico em cadeia, que favoreceria sua aplicação no contexto da civil law; e (3) pela abordagem da história constitucional por meio de narrativas literárias, em contraposição ao levantamento e à análise apenas de textos especificamente jurídicos.

Palavras-chave: Constitucionalismo. Hermenêutica. História. Literatura.

* Doutora em Estudos Literários (UFRGS). Mestre em Teoria Literária (PUCRS). Professora do Programa de Pós-Graduação em Direito da UniFG. Professora colaboradora do Programa de pós-Graduação em Letras da UFRGS. Líder do Grupo de Pesquisa Ser-Tão - Núcleo Baiano de direito e Literatura (DGP/CNPq). E-mail: $<$ h.karam@terra.com.br>.http://orcid.org/0000-0002-2166-1321

** Mestrando do Programa de Pós-Graduação em Direito da UniFG (BA). Membro do Ser-Tão - Núcleo Baiano de direito e Literatura. Bolsista CAPES-PROSUP. E-mail: <guilhermealcantara@msn.com>. http://orcid. org/0000-0002-2210-1270 


\section{CONSIDERAÇÕES INICIAIS: OS IMPASSES DE UMA CONSTITUIÇÃO TRINTENÁRIA}

Mais do que fruto de uma ideologia, o Constitucionalismo Contemporâneo resulta do giro copernicano promovido pelas lutas em prol da repolitização da legitimidade do direito pós-ditatorial (BONAVIDES, 2001), nas sociedades que, social e culturalmente plurais (OLIVEIRA, 2002), estão inseridas em contextos de modernidade tardia e nas quais a garantia para todos os cidadãos dos direitos individuais, políticos, sociais, econômicos, culturais e transindividuais não passou de um simulacro (STRECK, 2014). Nesse sentido, a Constituição Federal de 1988, ao institucionalizar os poderes selvagens - a moral, a economia, a política -, inimigos históricos do constitucionalismo brasileiro, constrói uma blindagem contra eles (STRECK, 2017).

Passados trinta anos da promulgação da Constituição de 1988, cabe a pergunta: o que há para comemorar? Certamente, a Constituição cidadã implementou algumas de suas promessas nesses trinta anos, porém não se pode negar que, desde que ela foi promulgada, a doutrina e a legislação infraconstitucional fizeram pouco jus ao seu potencial emancipatório. Comparato (1997) - ante a promulgação da Emenda Constitucional n ${ }^{0} 16$, de 4 de junho de 1997, que reintroduziu no sistema político nacional a reeleição do Presidente da República - chegou a declarar a morte da constituição antes que ela tivesse completado seus dez anos.

O protesto se repetiu quando a Constituição completou quinze anos. Lenio Streck apontou a ausência da adequada pré-compreensão do constitucionalismo contemporâneo, que atuaria como balizadora do sentido dos textos. O que se observa, segundo Streck, é que os intérpretes dos dispositivos constitucionais obstaculizam sua efetivação ao enxergarem a recém-nascida Constituição com os olhos do velho paradigma paleopositivista, sendo essa baixa compreensão da virada paradigmática efetuada no constitucionalismo brasileiro, em 1988, que produz como resultado inexorável o esvaziamento da força normativa da Constituição.

Hoje, em tempos de "cruzadas contra a corrupção", de "neo"constitucionalismo(s) e de maciças propagandas (neo) liberais, parece mesmo que a Constituição não existe. Os direitos e as garantias individuais são suplantados pelo discurso da impunidade (o direito a reboque de moralismos); os direitos e as garantias sociais, econômicas e culturais sucumbem diante dos discursos políticos ou economicistas que negam o dirigismo constitucional (direito a reboque do mercado).

As teorias constitucionais sofrem da crise de dupla face tão referida por Streck (2014, 2002). O texto constitucional, alvo constante de malabarismos hermenêuticos, é usado "literalmente", "historicamente", "finalisticamente" e de outros infinitos modos que inventar e quiser o leitor-intérprete-aplicador (direito a reboque da consciência do juiz, administrador ou legislador). Ante tal cenário, não se reduz o que há para comemorar?

Todavia, nunca se falou tanto da Constituição. A politização do direito, que é a outra face da judicialização da política, colocou a Carta de 1988 na "boca do povo". Qualquer pessoa na rua tem um pré-juízo até bem delineado - embora possa ser inautêntico - do que é uma constituição e do que está escrito na Constituição brasileira de 1988. 
Tal contexto institui a era da comunidade aberta dos intérpretes constitucionais a que alude Haberle (1997) e promove o espaço propício à luta por uma cultura de direitos os quais são assegurados nas constituições. No entanto, à medida que a comunidade jurídica brasileira ignora a revolução paradigmática que a Constituição de 1988 representa, evidencia-se a ausência de uma cultura apta a recepcioná-la (SILVA NETO, 2015).

Daí decorre a relevância de investigar formulações teóricas que viabilizem a superação desse impasse. No presente artigo, parte-se da premissa de que a construção de uma cultura constitucional digna da sociedade aberta de intérpretes perpassa pela triangulação entre direito, história e literatura em prol da adequada compreensão do texto constitucional.

Nesse sentido, cumpre destacar que a relação entre direito constitucional e história é assumida, de Freire (1894) a Bonavides e Andrade (1991), porém a relação entre história-direito e literatura foi ignorada pelos historiadores e juristas, sendo reconhecida e desenvolvida somente a partir dos anos 70 .

Assim, aproveitando o profícuo contexto de discussões promovido pela comemoração dos trinta anos da Constituição de 1988, a proposta, aqui, é lançar luz às interlocuções entre direito, história e literatura, a partir do giro ontológico-hermenêutico efetuado por Gadamer (1997, 2002), com o objetivo de encontrar alternativas que possibilitem superar os impasses que marcam o constitucionalismo brasileiro na atualidade.

Na primeira parte do texto, será exposto o modo ou os modos como a história ou a historiografia se relaciona com a literatura. A segunda parte é dedicada ao mesmo tipo de análise, no entanto aborda as relações entre direito e literatura. Na terceira e última parte, é apresentada a posição-limite que a literatura ocupa na hermenêutica filosófica, marco teórico dentro do qual história, literatura e direito podem contribuir para a renovação da história constitucional e, assim, para a construção de uma cultura constitucional no Brasil.

\section{HISTÓRIA E LITERATURA}

O ensaio Conhecimento histórico e historiografia brasileira contemporânea, de Martins (2011), apresenta quatro sentidos para o termo história. $\mathrm{O}$ mais universal, situado no âmbito da reflexão filosófica, denota o conjunto da existência humana no tempo, razão pela qual se fala comumente em "curso da história". O segundo, mais restritivo, vincula-se à memória que, carregada de elementos políticos, permite aos sujeitos se identificarem pessoal e socialmente. Em terceiro lugar, história é teoria da história, a historiografia, ${ }^{1}$ cuja existência depende do padrão de cientificidade - cartesiano ou empirista - que a modernidade nos legou, sendo o conceito mais técnico e restrito de história. Por último, o quarto sentido remete à cadeia de eventos ou de ações que compõe toda e qualquer narrativa.

Agamben (2005, p. 25) destaca que a ciência moderna "nasce de uma desconfiança sem precedentes em relação à experiência como era tradicionalmente entendida" e, promovendo a expropriação da experiência, institui a ideia de experimento: sucumbe, assim, a concepção de experiência que envolvia a narrativa de um evento único, sustentada na autoridade de 
quem a contava (AGAMBEN, 2005), e floresce a concepção de comprovação científica da experiência por intermédio do experimento.

Como resultado dessa cisão entre experiência e ciência, as diversas escolas de historiografia do século XIX coincidem na proposta de abandonar, em seus estudos, os testemunhos legados pelas gerações e considerar a atividade do historiador similar à do investigador (MARTINS, 2011).

Sob a inspiração positivista das ciências naturais, a historiografia busca - assim como todas as demais ciências - fundar sua cientificidade no signo do método, elemento concebido como garantidor da objetividade do conhecimento de um sujeito (do conhecimento) sobre o objeto (a ser conhecido). A partir do século XIX, então, a historiografia desenvolverá "métodos sistemáticos de críticas das fontes, das evidências que registravam as experiências do passado humano." (BARROS, 2001, p. 54). O principal debate da historiografia novecentista incidiu sobre a definição dos tipos de documentos ou de fontes históricas que, ao serem utilizados para sustentar as hipóteses da pesquisa histórica, pudessem ser submetidos à prova de verificabilidade, anulando a distância entre o mundo presente em que se insere o historiador e o mundo passado, que é o objeto da investigação (BARROS, 2001).

A busca da verdade no campo da historiografia principia, nesse sentido, com a busca por uma fundamentação metódico-documental que excluía os textos ficcionais como fonte válida de conhecimento histórico. Nas palavras de Harlan (2014, p. 13, grifo do autor), "os historiadores pensavam haver escapado ao meramente literário, [...] eles haviam estabelecido os estudos históricos no sólido fundamento do método objetivo e do argumento racional."

Mesmo a historiografia da primeira metade do século XX, a marxista ou a dos Annales, geralmente considerada uma reação ao positivismo, não deixou de desprezar a forma literária na escritura da história. Assim, destaca Benatte (2014), em História, ciência, escritura e politica, que a falsa narrativa dos textos literários se opõe à historiografia, a qual corresponde à narrativa histórica verdadeira, aquela que se adequa aos fatos. Para os historiadores do fim do século XIX e início do XX, o "perfeito manual metodológico" era a Introdução aos estudos históricos, de Charles Victor Langlois e Charles Seignobos, obra publicada em 1898 e traduzida para diversos idiomas, sendo utilizada ainda na década de 60 na bibliografia básica dos estudantes do Curso de História da USP.

Essa "bíblia" dos historiadores de então condenava as pretensões literárias dos estudos e das pesquisas da historiografia, em defesa da cientificidade. Os estudos históricos feitos antes de meados dos anos 1850 defendem Langlois e Seignobos (1946), não passavam de "literatura", material anticientífico, uma vez que os textos produzidos pela historiografia deveriam ser objetivos e claros.

Isso tudo sofreu severa ruptura a partir dos anos 70. No projeto da hermenêutica filosófica, lançado em Verdade e método, Gadamer (1997) reconhece como literatura toda produção escrita que participa da tradição linguística. O caráter de escritura tanto da obra artística quanto da obra científica vincula o texto ao seu receptor, intérprete ou leitor, que, antes de 
se conscientizar do caráter "documental" ou "artístico" do material que tem diante de si, procura compreender o que ele diz/propõe, a partir do significado de seu conteúdo. Nesse sentido, afirma Gadamer (1997, p. 261) que "a compreensão de textos, como, por exemplo, aquela que o historiador agencia não difere tanto da experiência da arte.” De tal modo que a literatura ocupa a posição-limite em que se faz a passagem entre arte e ciência, conforme será abordado adiante.

O fato é que o giro ontológico-hermenêutico efetuado por Gadamer resultou em profícuas relações interdisciplinares entre história e literatura. A história da literatura, obviamente, não raro era exercida pelos próprios críticos literários desde o século XIX e não constitui grande novidade. Em contrapartida o reconhecimento do caráter inexoravelmente literário, retórico ou poético dos escritos historiográficos não pode mais ser negado: ${ }^{2}$ tem-se, aí, a história como literatura.

Segundo Benatte (2014, p. 67), "O historiador sempre fora, desde a antiguidade clássica, um narrador", de tal modo que resulta inviável os historiadores negarem a própria estrutura narrativa de seus textos. O mesmo ocorre com os juristas, como se verá. Hayden White (1992) é um dos historiadores da geração pós-gadameriana que destaca, a partir do conceito de meta-história, a estrutura verbal da prosa narrativa dos textos historiográficos. Para Hayden White (2003, p. 139), a historiografia perdeu de vista suas origens literárias e deve resgatá-las sob pena de continuar sem sua principal fonte de força e renovação: a poética.

Outro ponto a destacar são as mudanças promovidas na relação história-literatura sob a perspectiva das produções literárias. Se o romance histórico do início do séc. XIX se caracteriza pela idealização e pela exaltação de um passado heroico, vinculadas ao processo de consolidação das identidades nacionais; ${ }^{3}$ no contexto contemporâneo, ele é reinventado pelo pós-modernismo, dando origem à metaficção historiográfica, ${ }^{4}$ sendo o revisionismo histórico seu traço essencial.

No âmbito das discussões teóricas, a aproximação da história com a literatura configura-se a partir de algumas questões basilares relativas à narrativa historiográfica: (1) o caráter representacional; 5 (2) a reconstrução imaginativa; ${ }^{6}$ (3) as falácias da neutralidade e da objetividade. ${ }^{7}$

Paralelamente a tais debates, obras literárias começaram a ser utilizadas como fonte de estudos históricos, e um dos precursores desse tipo de pesquisa no Brasil foi Gilberto Freyre. Nas palavras do autor que constam no prefácio à primeira edição de Casa grande e senzala, publicado em 1933, tem-se:

De outras fontes de informações ou simplesmente de sugestões, pode servir-se o estudioso da vida íntima e da moral sexual no Brasil dos tempos de escravidão: do folclore rural nas zonas mais coloridas pelo trabalho escravo; dos livros e cadernos manuscritos de modinhas e receitas de bolo, das coleções de jornais; dos livros de etiqueta; e finalmente do romance brasileiro que nas páginas de alguns dos seus maiores mestres recolheu muito detalhe interessante da vida e dos costumes da antiga família patriarcal [...]. José de Alencar em Mãe, Luciola, Senhora, Demônio familiar, Tronco do ipê, Sonhos de ouro, Pata da gazela (FREYRE, 2005, p. 49). 
Já Faoro (1976) estudou a história na ou através da literatura de Machado de Assis em Machado de Assis: a pirâmide e o trapézio. Gledson (2003) e Chalhoub (2003) são outras referências mais atuais e sofisticadas teoricamente que, também tendo por base os textos de Machado, investigam o contexto histórico brasileiro do Segundo Reinado até a Primeira ou "Velha" República.

\section{DIREITO E LITERATURA}

Faz parte de senso comum teórico dos juristas colocar (a teoria d)o direito no terreno da ordem e da realidade, enquanto a obra (de arte) literária pertenceria à ficção, ao lúdico. Esse abismo, fundado pelo pensamento positivista, sempre impediu que se levassem a sério os estudos de direito e literatura. O que aparentemente obstaria os estudos e pesquisas em direito e literatura seria o fato de que o direito corresponde a um discurso lógico-pragmático, enquanto a literatura, a um discurso ilógico e não-pragmático.

Tal perspectiva concebe, porém, tanto o direito quanto a literatura unilateralmente, cabendo à hermenêutica a (re)habilitação de um olhar mais completo sobre esses fenômenos. ${ }^{8}$

Em primeiro lugar, a consideração de que o direito é (essencialmente) um discurso lógico-pragmático permanece refém do que Dworkin (1999, p. 55 et seq.) chamou de aguilhão semântico. Dworkin há muito destacou - e hoje o faz, além de Streck, Nelson Saldanha - que no direito a relação entre teoria e prática é interpretativa, isto é, "a prática [...] tem que ver com princípios e/ou normas" (SALDANHA, 2003, p. 232, grifo do autor), e sua projeção sobre o real depende da (pré-)compreensão de cada intérprete. Assim, "a própria configuração do real, tanto no caso da política como no caso do direito, resulta de um modo de ver que projeta de si alguma visão interpretativa." (SALDANHA, 2003, p. 232, grifo do autor).

Embora o direito certamente tenha sempre se manifestado em qualquer grupo humano como ordem, ${ }^{9}$ isto é, como "organização normativa da estrutura social e que, portanto, ordena comportamentos, adotando valores e prevendo soluções" (SALDANHA, 2003, p. 300), com uma lógica específica, a elaboração e imposição das regras jurídicas sempre implica uma consciência hermenêutica. Logo, só é possível considerar o fenômeno jurídico em sua completude considerando-o "uma variável e especial conjugação de ordem e hermenêutica" (SALDANHA, 2003, p. 300). Afinal, como destaca Vespaziani (2015, p. 82),

A vida do direito oscila entre as exigências de fechamento do nomos imperial e as exigência de abertura do nomos paideico, e a principal contribuição dos estudos do Direito e Literatura consiste, precisamente, na constante reabertura de discursos, possibilidades e mundos de vida, que as exigências institucionais e o discurso do poder sempre tentam encerrar.

Em segundo lugar, a obra de arte não é somente ficção que dissimula a realidade. Uma das funções da Literatura - como de toda obra de arte - é ser subversiva. Ela exerce a tentação de - por meio de uma linguagem deformada e autorreferencial - reconsiderar o óbvio ou as fronteiras do que é chamado de realidade (BRUNER, 2014, p. 20; WARAT, 1985), 
residindo aí, pois, sua utilidade para problematizar as concepções de mundo cristalizadas na cultura, para descontruir as ideologias que subjazem aos discursos homogêneos e, consequentemente, para (re)volver as sedimentações do senso comum teórico dos juristas.

Também parece óbvio que a Literatura - assim como toda obra de arte - deve ser inútil, no sentido de que não se lê um romance com os mesmos objetivos de quando é lido um manual de direito, uma lei ou uma sentença judicial, pois estes são pragmáticos (EAGLETON, 2006, p. 12-13). Porém, mais uma vez, trata-se de uma visão incompleta do fenômeno literário. Mesmo que a Literatura provoque o que Jerome Bruner denomina subjuntivização da realidade, isto é, a (re)produção não do que é, mas do que pode(ria) ser, a compreensão do significado ou sentido da obra literária pressupõe uma tradição comum que é transmitida pela escrita. Em outras palavras, "para alcançar seu efeito, a narrativa literária deve fincar suas raízes em terreno familiar, no aparentemente real.” (BRUNER, 2014, p. 21).

Ademais, como alerta Bruner (2014, p. 17), "não deveríamos minimizar o poder das histórias para moldar a experiência cotidiana.” É preciso considerar que a compreensão de conceitos como Constituição e romance dependem de sua inclusão em universos narrativos e que, se a narrativa literária contribui para dar forma às coisas do mundo real, o direito - tanto no cotidiano forense ${ }^{10}$ quanto nos manuais - utiliza-se, assim como a literatura, de artifícios da grande ficção para compreender seus conceitos (BRUNER, 2014, p. 22).

De fato, na experiência artística se dá algo mais, que Terry Eagleton denomina experiência não-pragmática e que Gadamer caracteriza como ver-se afetado pelo sentido do dito. Afinal, a linguagem da arte

fala à autocompreensão própria de cada um, e o faz como atual em cada caso e através da sua própria atualidade. Sem dúvida, precisamente sua atualidade permite à obra converter-se em linguagem. [...] a obra de arte reflete ao excesso de sentido que se apoia na obra mesma. [...] Isso tem um significado fundamental e, nessa medida, a estética é um elemento importante da hermenêutica geral (GADAMER, 1996, p. 9).

Evidencia-se, assim, que o giro hermenêutico promovido por Gadamer na filosofia encontra-se umbilicalmente vinculado ao giro narrativo ${ }^{11}$ que, efetuado no campo do direito, constitui o produto mais expressivo do movimento norte-americano intitulado Critical Legal Studies (CLS).

No contexto jurídico europeu, a concepção narrativista do direito é desenvolvida por González (2013), que alerta para o fato de o direito possuir natureza e propriedades narrativas e defende seu caráter ficcional

Para a Teoria Narrativista do direito é importante explicar e compreender que nossos sistemas jurídicos são instalações ficcionais e, às vezes, hiperficcionais. Dessa maneira, a Teoria Narrativista do direito sustenta que esse é forma linguística ficcional de um mundo puramente textual; o corpus juris é uma categoria discursivo-narrativa [...]. direito e Literatura se entretecem a partir da comum poeticidade institucional capaz de elaborar ficções sociais que, como figurações reais $[\ldots]$ instituem novas condições no mundo "real" e, em acréscimo, com 
amplas possibilidades de se imporem totalmente ao mundo "real" (GONZÁLEZ, 2013, p. 56, grifo do autor).

Também Robert Cover, em seu seminal Nomos e narrativa, já salientara que o direito - por ser uma variante especial de ordem e hermenêutica - não se compõe somente de um corpus juris, mas também de

narrações que situam o corpus juris sobre aqueles que expressam suas vontades através dele, $[\ldots .$.$] estabelecem os paradigmas para o comportamento [...] cons-$ troem relações entre o universo normativo e o material, entre as restrições da realidade e as demandas por uma ética. Esses mitos estabelecem um repertório de movimentos - um léxico de ação normativa - que podem ser combinados em padrões de significado derivados de estruturas de significado herdadas do passado (COVER, 2016, p. 193).

Essas narrativas herdadas do passado comprovam que não há um grau zero de sentido. Há uma tradição que nelas transparece, e a tradição escrita - literária, pois, lato sensu - distingue-se por não sofrer os desgastes e as deturpações do tempo, visto que, embora suscetível à revisão, "Quem sabe ler o que foi transmitido por escrito atesta e realiza a pura atualidade do passado." (GADAMER, 1997, p. 262).

$\mathrm{Na}$ verdade, não constitui exagero afirmar que a obra de arte literária - sem deixar de ser especulativa e não-pragmática - situa-se também em um universo normativo, a seu modo ${ }^{12}$ (COVER, 2016), contém uma verdade que é (des) velada pela sua linguagem (GADAMER, 1997, 2002) e, o mais importante, oferece as credenciais de acesso à realidade (BRUNER, 2014), sendo também uma conjugação de ordem e hermenêutica. Diferente do direito, sim, mas semelhante a ele nesse aspecto. Tal semelhança é o ponto-chave para a abordagem do tema do constitucionalismo através da literatura, sob a mediação hermenêutica.

Ressaltam-se, ainda, as inúmeras experiências proporcionadas pelo relacionamento entre as disciplinas direito e literatura. ${ }^{13} \mathrm{~A}$ união das duas disciplinas possibilita o resgate das raízes da cultura, contribuindo para a compreensão da construção imaginária que institui a sociedade (OST, 2004, p. 58).

Além disso, o texto literário, muitas vezes, ilustra de modo privilegiado questões jurídicas, colocando o jurista em paralaxe, ${ }^{14}$ assim como constitui "importante forma de resistência contra a violação de direitos fundamentais e dos ideais democráticos"15 (TRINDADE; GUBERT, 2008, p. 62), ao colaborar para a (re)construção da moralidade política (WEST, 1988).

Afinal, a literatura, afirma Resta (2008), mesmo no seu realismo mais cru, ainda assim trabalha sobre possibilidades, o que a torna o "maior e mais autêntico observatório social". As ciências sociais, portanto, deveriam adquirir estilos narrativos, capazes de aproximá-las desse infinito mundo de possibilidades que nenhuma teoria analítica (ou econômica) do direito jamais pôde decifrar sob seus modelos conceituais. ${ }^{16}$

Com base nessas considerações, pode-se constatar a dupla relação que o direito e a literatura mantêm, mesmo que não reconhecidas. Em primeiro lugar, o discurso jurídico, assim como o discurso do historiador, é intrinsecamente narrativo e tem sua origem na poética 
- o direito como literatura, abordado, entre outros, por Boyd White (1973). Esse é um fato que muitos juristas ignoram. ${ }^{17}$

A outra face dessa relação é a do direito na ou através da literatura. Os textos literários possuem um poder premonitório das catástrofes humanas (WEISBERG, 1984) e sempre apresentam uma agenda social e política (WARD, 1995).

Evidencia-se, assim, que tanto o direito quanto a história estão inquestionavelmente relacionados com a literatura. Uma vez reconhecidos esses vínculos inexoráveis, torna-se possível projetar a triangulação das três disciplinas. Mas, para tanto, seria necessário ainda elucidar o que permite a conjugação não apenas entre direito e literatura, história e literatura, direito e história, mas entre direito-literatura-história, tema a ser abordado na sequência.

\section{O CARÁTER UNIVERSAL DA HERMENÊUTICA E A POSIÇÃO-LIMITE DA LITERATURA}

O ser que pode ser compreendido é linguagem. Evocando essa famosa frase de Gadamer, é possível introduzir o problema da universalidade da hermenêutica, tema exaustivamente trabalhado nos dois volumes de Verdade e método e também em escritos posteriores, como Estética e hermenêutica.

No tópico intitulado $\mathrm{O}$ aspecto universal da hermenêutica filosófica, que encerra e sintetiza o primeiro volume de Verdade e método, Gadamer defende uma estrutura especulativa da linguagem, "que consiste não em ser cópia de algo que está dado de modo fixo, mas em um vir-à-fala, onde se anuncia um todo de sentido." (GADAMER, 1997, p. 686-687). Fica estabelecido, assim, o caráter produtivo - não somente reprodutivo - da interpretação.

O axioma o ser que pode ser compreendido é linguagem serve, pois, sobretudo, para refutar o esquema sujeito-objeto e toda a epistemologia que dele deriva. ${ }^{18} \mathrm{~A}$ linguagem, para a hermenêutica filosófica desenvolvida por Gadamer, atinge seu significado ontológico-universal quando se reconhece que "o que vem à fala é, naturalmente, algo diferente da própria palavra falada." (GADAMER, 1997, p. 688). A experiência linguística atesta a tese heideggeriana da diferença ontológica entre ser e ente.

A partir desse giro ontológico-linguístico, a compreensão dos textos não poderia se restringir à ideia do esforço imanente de uma consciência filológica indiferente à verdade e tampouco seria cabível pré-julgar "a questão da verdade, a partir do ponto de vista de um conhecimento superior da coisa" (GADAMER, 1997, p. 701), em que se visa somente à sua satisfação. Desse modo, a compreensão não se reduz ao virtuoso exercício e domínio técnico do que está escrito, trata-se, ao contrário, do encontro com algo que vale como verdade. Assim, o processo linguístico é de certo modo semelhante ao jogo, ${ }^{19} \mathrm{um}$ jogo de palavras que circunscreve o que se quer dizer.

Em A universalidade do problema hermenêutico, conferência incluída no segundo volume de Verdade e método, Gadamer aprofunda tais questões. Ao deixar claro seu objetivo de alçar a hermenêutica à categoria de problema universal, desvincula a hermenêutica da posição de 
mera tarefa a serviço da ciência da interpretação e destaca que sua função é "reconduzir nosso mundo atual, colocado à disposição e arbítrio pela ciência, esse mundo que chamamos de técnica, às ordenações fundamentais do nosso ser" (GADAMER, 2002, p. 255).

A questão da consciência estética é retomada, mais uma vez, no intuito de demonstrar como a experiência com a tradição artística precede a formulação dos julgamentos estéticos operados por essa consciência. Afinal, "A consciência da arte, a consciência estética é sempre secundária. É secundária frente à imediata pretensão de verdade que provém da obra de arte" (GADAMER, 2002, p. 256). Acrescente-se ainda que, segundo Gadamer, julgar algo a partir da sua qualidade estética deixa de lado "alguma coisa que nos atinge muito mais intimamente" (GADAMER, 2002, p. 256).

Isso não significa que a hermenêutica filosófica, por ver além da ciência moderna, deva lhe impor diretrizes de desenvolvimento, pois Gadamer enfatiza, justamente, que "a ciência não fará nossa vontade" (GADAMER, 2002, p. 262). O que a hermenêutica filosófica viabiliza é impedir que a civilização moderna, baseada na ciência - movida pelo puro desejo de conhecer ou, em termos nietzscheanos, pela vontade de verdade -, negligencie a tradição linguística nas consciências histórica e estética, e o faz estabelecendo as "pressuposições sob as quais se encontram as possibilidades de conhecimento e de produção" (GADAMER, 2002, p. 262), a fim de que a mão que emprega tais conhecimentos não se torne destrutiva.

As pessoas só podem ter uma autêntica associação porque elas são para si círculos de linguagem, os quais "se tocam e vão fundindo cada vez mais", sobrando sempre novamente linguagem. Existe, portanto, um diálogo infinito na compreensão. Tal diálogo é, justamente, o que caracteriza a dimensão fundamental do elemento hermenêutico, pois a "tarefa comum dos homens é criar uma linguagem autêntica, que tem algo a dizer e [que] por isso [...] procura palavras pelas quais possa alcançar o outro", tarefa que Gadamer afirma ser mais relevante para "quem busca trazer à fala uma tradição escrita" (GADAMER, 2002, p. 269-270), como é o caso do jurista, do historiador e do literato.

Também a história assume relevância na hermenêutica filosófica, tendo em vista que, como destaca Stein (2014, p. 224), "o todo da cultura humana deve ser compreendido como envolvido num acontecer da historicidade de um sentido que nunca recuperamos em sua plenitude." Isso porque a consciência histórica, ao colocar-se diante dos testemunhos de uma época e tentar compreender o espírito dessa época, mesmo que a desvincule essa época da realidade presente, não esgota toda a tarefa da compreensão do passado e de sua tradição.

Quando Gadamer propõe uma consciência hermenêutica, portanto, está postulando uma possibilidade mais abrangente. Não se trata, apenas, de superar a redução teórico-científica que conduz as consciências artística e histórica, mas também de superar a concepção de hermenêutica como ciência da interpretação. Para ele, enquanto "a ciência da hermenêutica quer-nos fazer crer que o texto que devemos compreender seria algo estranho, que tenta induzir-nos a mal-entendidos", a consciência hermenêutica visa a "evitar os pressupostos que estão à base 
da consciência estética, da consciência histórica e da técnica de evitar os mal-entendidos, superando assim as alienações presentes neles" (GADAMER, 2002, p. 260).

O conceito de literatura, nos lembra Gadamer, é muito mais amplo do que o da obra de arte literária. Nele está incluído tudo que faz parte da tradição linguística, não apenas os textos religiosos, jurídicos, econômicos, públicos e privados de todo tipo, mas também a denominada prosa científica, ou seja, aqueles textos que abordam e interpretam cientificamente os textos religiosos, jurídicos, históricos, literários etc. Na medida em que a literatura, na concepção gadameriana, é todo texto que se vincula à tradição linguística, ela ocupa uma posição-limite na compreensão, o que lhe outorga um status fundamental para a hermenêutica (GADAMER, 1997, p. 259).

Gadamer, evidentemente, reconhece as diferenças entre a linguagem da poesia e a da prosa, bem como as diferenças entre a linguagem da prosa poética e a da prosa científica. Ele reconhece, também, que cada uma delas reivindica a verdade - ou o seu tipo de verdade - a seu modo, mas a questão fundamental que se coloca é aquilo que as aproxima: uma profunda comunhão entre todas as obras literárias, que reside "no fato de que a formulação linguística permite que o significado que deve ser expresso chegue a ser operante." (GADAMER, 1997, p. 259).

Nesse sentido, a literatura constitui o ponto de estofo em que a arte e a ciência encontram passagem de uma para outra, impondo, seja ao leitor de um romance ou ao historiador ante um texto, seja a um investidor da bolsa de valores que lê o jornal ou, ainda, ao advogado que examina uma sentença, uma tarefa muito específica: compreender aquilo que foi transmitido pela escrita (GADAMER, 1997, p. 260).

\section{CONSIDERAÇÕES FINAIS - QUE POSIÇÕES PODEM TOMAR DIREITO- -LITERATURA-HISTÓRIA?}

Warat (1985), com seu A ciência jurídica e seus dois maridos, já havia proposto a metáfora em que a ciência jurídica, Dona Flor, mantém dupla relação: com Teodoro, a positivista e metódica dogmática jurídica; e com Vadinho, a representação da literasofia, uma filosofia do direito fundada na arte, na poesia e na literatura.

A proposta deste artigo aposta em outra perspectiva: ao invés de abordar o necessário equilíbrio, no âmbito do direito, entre as dimensões apolínea e dionisíaca, buscou-se destacar a necessidade de contemplar e incorporar as narrativas literárias nas pesquisas dedicadas à história do direito, sobretudo no caso do direito constitucional. A pesquisa histórica do direito brasileiro tem se mantido no campo da análise dos documentos oficiais (constituições, leis, regulamentos, discursos, decisões administrativas ou judiciais e doutrina jurídica), uma análise, portanto, das fórmulas e ritos, das formas pelas quais as instituições políticas legitimam seus atos ao longo do tempo. A relação entre direito e história, nesse sentido, é extremamente formal e positivista. 
Considerado o giro ontológico-linguístico efetuado pela hermenêutica na filosofia, o caráter de escritura da literatura é o que atrai e permite a compreensão da história e, obviamente, do direito. Certamente, direito, história e literatura são estruturados cada um por linguagem própria, mas o giro hermenêutico contempla um nível mais profundo, demonstrando que a compreensão do conteúdo do significado do texto que se lê é um ato comum ao historiador, ao jurista e ao crítico literário.

A hermenêutica filosófica, nesse sentido, oferece o terreno comum que viabiliza a conjugação entre as três disciplinas. De tal modo que, paralelamente ao reconhecimento de que juristas, historiadores e escritores ou críticos de obras literárias não atuam sozinhos, impõe-se instituir e desenvolver relações que não comprometam a autonomia de cada um dos campos. O que segue nestas conclusões é apenas um exercício de projeção que não esgota as possibilidades de interlocução entre as disciplinas e que incide, particularmente, na esfera do direito constitucional, que ocupa - ou deveria ocupar - posição de destaque na teoria jurídica.

Em primeiro lugar, é possível empregar conceitos e metodologias da teoria literária no exame dos textos de história do direito, abordando seu caráter inexoravelmente narrativo. Tais estudos se inscreveriam no campo da literatura da história do direito e viabilizariam elaborar, recorrendo à conceituação de Hayden White (1992), uma metahistória jurídica.

Ademais, existe a possibilidade de acrescentar novo elemento à metáfora da integridade do direito como romance em cadeia, de Dworkin (2000). Extrai-se, a partir do exposto no presente trabalho, que a metáfora é muito melhor compreendida - uma vez reconhecida a historicidade do direito pelo constitucionalismo pós-bélico - como romance histórico em cadeia. Afinal, o resgate do passado institucional do direito é essencial para a teoria dworkiniana da decisão correta. Esse seria o campo do estudo do direito como literatura na história.

Por último, configura-se o campo do estudo da história do direito na literatura, que implicaria sair do âmbito tradicional da pesquisa histórica, ainda presa à fundamentação metódica-documental, e - no rastro de Freyre, Faoro, Gledson e Chalhoub - procurar, na prosa fictícia nacional, vestígios da história do constitucionalismo brasileiro. Ao desviar o olhar dos textos constitucionais, legais e jurisprudenciais e enfocar a literatura, o historiador do direito encontrará narrativas que antes ignorava. Tratar-se-ia de escovar a história a contrapelo, nos termos de Benjamin (1994), isto é, de reconhecer, por meio de narrativas literárias, um constitucionalismo de ficções - em contraposição ao discurso dominante do constitucionalismo - com o objetivo de (re)habilitar a história constitucional do país e, assim, construir uma cultura constitucional.

O rol apresentado é apenas um esboço, mas, acredita-se, já evidencia, suficientemente, o amplo espectro de questões a serem abarcadas pelos estudos e pesquisas que adotem a triangulação entre história, direito e literatura, bem como seu potencial de problematização na esfera jurídica. 


\title{
HISTORY, LAW AND LITERATURE: A TRIANGULATION IN SUPPORT OF CONSTITUTIONALISM
}

\begin{abstract}
This article, with an interdisciplinary bias, aims to examine the ways in which Literature is incorporated into the historiographic studies of Law, particularly with regard to the sphere of Constitutional Law. Based on the assumption that History and Law have always been close although such proximity is not commonly recognized - it is argued that the dialogue between Historiography of Law and Literature is an essential way to overcome impasses and to advance in the construction of an adequate constitutional culture to late Brazilian modernity. In order to do so, we examine, through bibliographic research, the intersections between History and Literature, as well as between Law and Literature, with an emphasis on the limiting position that Literature occupies in the scope of philosophical hermeneutics, a theoretical framework that makes the dialogue of these three disciplines feasible, so that the triangulation of History-LawLiterature is able to contribute to the renewal of Constitutional History and, consequently, to the construction of a constitutional culture in Brazil. It finishes by identifying three axes of study from the proposed triangulation, which are characterized by: (1) the use of concepts and methodologies derived from literary theory in examining the texts of the History of Law, addressing its inexorably narrative character; (2) the proposal to reformulate the metaphor of the integrity of Law as a historical chain-link novel, which would favor its application in the context of Civil Law; and (3) the approach of Constitutional History through literary narratives, as opposed to the collection and analysis of only specifically legal texts.
\end{abstract}

Keywords: Constitutionalism. Hermeneutics. History. Literature.

\section{HISTORIA, DERECHO Y LITERATURA: UNA TRIANGULACIÓN EN FAVOR DEL CONSTITUCIONALISMO}

\section{RESUMEN}

El presente artículo, de sesgo interdisciplinario, tiene como objetivo examinar los modos de incorporación de la Literatura a los estudios historiográficos del Derecho, particularmente en lo que se refiere a la esfera del Derecho Constitucional. A partir del supuesto de que Historia y Derecho siempre estuvieron cerca - aunque tal proximidad no sea comúnmente reconocida -, se defiende que la interlocución de la Historiografía del Derecho con la Literatura constituye una vía imprescindible para superar impasses y avanzar en la construcción de una cultura constitucional adecuada a la modernidad tardía brasileña. Para ello, se examinan, mediante investigación bibliográfica, las intersecciones entre Historia y Literatura, así como entre 
Derecho y Literatura, con énfasis en la posición-límite que la Literatura ocupa en el ámbito de la hermenéutica filosófica, marco teórico que viabiliza el diálogo de las tres disciplinas, posibilitando, a la triangulación Historia-Derecho-Literatura, contribuir a la renovación de la Historia Constitucional y, consecuentemente, a la construcción de una cultura constitucional en Brasil. Se concluye con la identificación de tres ejes de estudio de la propuesta de la triangulación, que se caracterizan por: (1) el uso de conceptos y metodologías de la teoría literaria en el examen de la Historia de los textos de Derecho, dirigiéndose a su carácter inexorablemente narrativo; (2) la propuesta de reformulación de la metáfora de la integridad del Derecho como novela histórica en cadena, que favorecería su aplicación en el contexto de la civil law; y (3) el abordaje de la Historia Constitucional a través de narrativas literarias, en contraposición al levantamiento y análisis sólo de textos específicamente jurídicos.

Palabras clave: Constitucionalismo. Hermenéutica. Historia. Literatura.

1 Segundo Martins (2011, p. 199, grifo do autor), "No caso do entendimento da História como uma disciplina metódica de pesquisa, com resultados intersubjetivamente controláveis (terceiro sentido), aplica-se, para o produto narrativo acabado, o termo, algo mais técnico, de historiografia. Trata-se do livro de História de que se fala quando tema, autor e forma metódica de tratamento do assunto ensejam determinado grau de confiabilidade somente efetivado na História como ciência."

2 A esse respeito, a historiadora Pesavento (2006, p. 14, grifo do autor). destaca: "o que vemos hoje, nesta nossa contemporaneidade, são historiadores que trabalham com o imaginário e que discutem não só o uso da literatura como acesso privilegiado ao passado - logo, tomando o não-acontecido para recuperar o que aconteceu! - como colocam em pauta a discussão do próprio caráter da história como uma forma de literatura, ou seja, como narrativa portadora de ficção!"

3 Lukács (2011) destaca que a participação das massas nas revoluções europeias ocorridas entre 1789 e 1814 propiciou nova percepção do homem como sujeito da história e que o sentimento histórico dela decorrente fundará as bases das narrativas produzidas na fase clássica do romance histórico.

4 O termo é cunhado por Linda Hutcheon, que considera a metaficção historiográfica a forma narrativa mais significativa da poética pós-modernista. Segundo Hutcheon (1991, p. 127), "A metaficção historiográfica refuta os métodos naturais, ou de senso comum, para distinguir entre o fato histórico e a ficção. Ela recusa a visão de que apenas a história tem uma pretensão de verdade, por meio do questionamento da base dessa pretensão na historiografia e por meio da afirmação de que tanto a história como a ficção são discursos, construtos humanos, sistemas de significação, e é a partir dessa identidade que as duas obtêm sua principal pretensão à verdade."

5 Conforme alerta Pesavento (2000, p. 7-8, grifo do autor), "história e literatura são formas de dizer a realidade e, portanto, partilham esta propriedade mágica da representação que é a de recriar o real, através de um mundo paralelo de sinais, construído de palavras e imagens. [...] É claro que tanto a história como a literatura têm métodos e exigências diferenciadas e que mesmo suas metas podem ser distintas. Mas se o historiador, na sua busca de construção de um conhecimento sobre o mundo, quer resgatar as sensibilidades de uma outra época, a maneira como os homens representavam a si próprios e à realidade, como não recorrer ao texto literário, que lhe poderá dar indícios dos sentimentos, das emoções, das maneiras de falar, dos códigos de conduta partilhados, da gestualidade e das ações sociais de um outro tempo? E, no caso, a literatura, como pode deixar de se voltar, também, para o resgate da narrativa histórica que, reconstruindo o passado ou inventando o futuro, persegue a verdade como projeto intelectual, revelando com isto a historicização das formas de uma escritura que busca dar ordem no mundo? Parece que as duas narrativas se empenham neste esforço de capturar a vida, reapresentar o real, mesmo que as suas estratégias de argumentação possam diferir."

6 Gottschalk (1969) aborda esse tópico salientar que, embora o método histórico consista do processo de exame e 
análise crítica dos "registros e relíquias do passado", a historiografia resulta da reconstrução imaginativa operada nesse processo.

7 A impossibilidade de neutralidade nos discursos produzidos por historiadores é apontada por Burke (1992, p. 337, grifo do autor), que afirma: "cada vez mais historiadores estão começando a perceber que seu trabalho não reproduz o que realmente aconteceu, tanto quanto o representa de um ponto de vista particular." De tal modo que é preciso considerar - diante da falta de liberdade dos historiadores para inventar personagens, bem como palavras e pensamentos de personalidades do mundo empírico - a necessidade de o historiador praticar, assim como o romancista, a heteroglossia, isto é, incorporar em seu relato vozes distintas e opostas. Já o tema da objetividade é examinado por Paul Ricoeur, para quem "A história é na verdade o reino do inexato. Essa descoberta não é inútil, ela justifica o historiador. Justifica todas as suas incertezas $\mathrm{O}$ método histórico não pode ser senão um método inexato. [...] A história quer ser objetiva e não pode sê-lo. Quer fazer reviver e só pode reconstruir". No original: "L'histoire est réellement le royaume de l'inexact. Cette découverte n'est pas vaine; elle justifie l'historien. Elle le justifie de tous ses embarras. La méthode historique ne peut être qu'une méthode inexacte. [...] L'histoire veut être objective, et elle ne peut pas l'être. Elle veut faire revivre et elle ne peut que reconstruire." (RICOEUR, 2001, p. 90-91).

8 A esse respeito, Schwartz (2006, p. 50) destaca o seguinte: "Como ambos são textos, direito e Literatura reclamam uma atividade que apure o sentido de suas construções, evidenciando a relação entre construtor/legislador e o destinatário/cidadão da norma jurídica. [...] o que os diferencia tem suporte na proposição de que do direito se espera o comando e da Literatura se espera o belo. Reduzir essa distância, permitindo o acoplamento entre o sistema jurídico e o sistema da arte, pode restaurar a essência das coisas, visto que as leis nascem das letras."

9 Nesse sentido, Cunha (2011, p. 15) assinala que "Constituição é estabilidade e ordem, e por isso ela tem de ter prevalência sobre todo o demais direito. Isso implica, para ser prático, que se deve fazer um juízo de constitucionalidade das leis. Não basta que a Constituição trace as grandes linhas de como deve ser o nosso País. É preciso que as leis, todas as leis, respeitem esse programa comum de todos, que é a Constituição."

10 Como alerta Cárcova (2008, p. 12, grifo do autor), "Una sentencia es un acto de naturaleza autoritativa, instituido por quien posee imperium. Sin embargo, se organiza como discurso, del mismo modo que el relato, la crónica o la narración se organizan como discurso. Y, pasada em autoridad de cosa juzgada [...] constituye la realidad jurídica de un modo muy semejante al que el novelista constituye la realidad de sus ficciones, o el cronista la de su crónica, al privilegiar algún dato, descartar otro, hipotetizar un tercero. No afirmamos que exista analogía entre ficción y realidad. Señalamos que la realidad está socialmente construida, sobre todo la que llamamos realidad social, que es siempre una realidad interpretada."

11 No mesmo sentido, Resta (2008, p. 40) entende a narrativa como um "mecanismo [linguístico] compartilhado pelo direito e pela psicanálise quem tem a fazer não com a estrutura, mas com o meio expressivo que o acompanha. [...] é justamente a narração que nos conduz a um ponto de encontro entre uma ordem relatada pela aparente certeza das normas e por mundos da vida, ricos, plurais, insondados, que são maiores e mais complexos do que se possa dizer aquela certeza. [...] a narração aparece de repente como produto e como meio, como representado e representante."

12 Destaca-se, aqui, que, segundo Cover (2016, p. 194, grifo do autor), "Os códigos que ligam o nosso sistema normativo às construções sociais da realidade e às visões do que o mundo poderia ser possuem natureza narrativa. A própria imposição de uma força narrativa sobre o estado de coisas, real ou imaginário, é um ato de criação normativa. Os vários gêneros de narrativa - história, ficção, tragédia, comédia - têm em comum a característica de ser a soma do estado de coisas afetado pela força de um campo normativo. Viver em um mundo normativo requer que uma pessoa tenha conhecimento não somente dos preceitos jurídicos básicos, mas também de suas conexões possíveis com a realidade social. Isso faz com que o indivíduo integre não somente o ser e o dever-ser, mas o ser, o dever-ser e o que poderá-ser. Portanto, a narrativa também integra esses domínios."

13 Com base na classificação proposta por Ost (2004), os estudos sobre direito e literatura dividem-se da seguinte forma: 1) direito na literatura, que enfocam a representação do universo jurídico em textos literários, assim como a abordagem de temáticas concernentes ao direito; 2) direito da literatura, que abarcam as normas de liberdade de expressão, de promoção da cultura e de direitos de autor; e 3) direito como literatura, que - prin- 
cipalmente a partir do giro narrativo - analisam as narrativas juridicas e se ocupam de aspectos relativos à teoria da decisão, borrando os limites formais entre as duas disciplinas. Já Schwartz (2006, p. 56-57), adotando uma concepção sistêmica, destaca que "O estudo do direito na Literatura é aquele que se apresenta como o mais construído e desenvolvido, pois, aqui, o acoplamento entre o sistema jurídico e o sistema da arte é latente, visto que existem imbricações bastante óbvias possibilitadas pela comunicação entre os textos. É o caso, por exemplo, quando um juiz cita uma obra literária para fundamentar sua decisão. E, vice-versa, quando um autor transforma em arte uma causa jurídica. Oferece-se, desse modo, ao sistema jurídico, uma observação de segundo grau, capaz de diferenciá-lo a partir de sua própria lógica, porém influenciado cognitivamente pelos fenômenos externos."

14 Segundo propõe Zizek (2008, p. 32, grifos do autor), a paralaxe consiste no "deslocamento aparente de um objeto (mudança de sua posição em relação ao fundo) causado pela mudança do ponto de observação que permite nova linha de visão. É claro que o viés filosófico a ser acrescentado é que a diferença observada não é simplesmente subjetiva, em razão do fato de que o mesmo objeto que existe lá fora é visto a partir de duas posturas ou pontos diferentes. Mais do que isso, como diria Hegel, sujeito e objeto são inerentemente mediados, de modo que uma mudança epistemológica do ponto de vista do sujeito sempre reflete a mudança ontológica do próprio objeto." No campo do direito, Trindade (2010, p. 28, grifo do autor) destaca que "a visão em paralaxe permite que se opere aquilo que se pode chamar de descondicionamento do olhar e, assim, possibilita que o juiz transcenda os limites (im)postos pelo sentido comum teórico, que estabelece um conjunto de pré-conceitos, crenças, standards, padrões, ficções, fetiches, hábitos, estereótipos e representações que, por intermédio da dogmática jurídica, disciplinam, anonimamente, a produção social da subjetividade dos juristas, amputando as possibilidades de interpretação, aplicação e compreensão do direito. Neste contexto, considerando a importância da interdisciplinaridade e recorrendo à noção de paralaxe, é que a Literatura exsurge como uma disciplina capaz de colaborar, sobremodo, para a formação de um novo paradigma jurídico."

15 Sobre isso, sustenta Candido (2011, p. 188) que "a literatura pode ser um instrumento consciente de desmascaramento, pelo fato de focalizar as situações de restrição dos direitos, ou de negação deles, como a miséria, a servidão, a mutilação espiritual. Tanto num nível quanto noutro ela tem muito a ver com a luta pelos direitos humanos."

16 Em sua análise, é destacado, ainda, que "O texto narrativo de direito, como qualquer outro texto, fala sobre si mesmo de maneira ambivalente: daquilo que diz a daquilo de que fala, daquilo que é, mas também daquilo que nele falta, das suas presenças e das suas ausências, e assim por diante. [...] quem quiser avaliar a dimensão, que é a mais relevante, desse doppelgänger deverá ler o texto jurídico não em sua redução a proposições técnicas, mas como narração." (RESTA, 2008, p. 53).

17 Resulta de tal desconhecimento que, "enquanto na teoria da literatura são adotados os conceitos de horizonte de sentido e de intersubjetividade, [...] prevalecem no direito construções teóricas que, blindadas ao linguistic turn e ao narrative turn, ignoram a superação da hermenêutica clássica." (KARAM, 2017, p. 1040).

18 Isso foi demonstrado por Gadamer também nos capítulos dedicados à análise da obra de arte e às ciências do espírito ou históricas, em oposição ao modelo moderno de conhecimento da natureza, que nada mais faz do que organizar, metodologicamente, as várias formas do ente, abstraída a nossa relação originária com o mundo que é fornecida pela experiência da linguagem. A pretensão moderna de se livrar de todos os preconceitos - que leva Descartes a duvidar de tudo o que nos é dado - é, em si, um preconceito, ainda que irrefletido, "que está implicado no ideal de objetividade que a ciência coloca", e é um preconceito ontológico, de que a hermenêutica filosófica pretende livrar toda reflexão, não apenas a estética e a histórica, pois "ser especulativo, distinguir-se de si mesmo, representar-se, ser linguagem que enuncia um sentido, tudo isso não o são somente a arte a história, mas todo ente, na medida em que pode ser compreendido." (GADAMER, 1997, p. 689-690, grifo do autor).

19 Vale lembrar que, para Gadamer, no jogo, a subjetividade do jogador é limitada pelo próprio jogar, na medida em que levar o jogo a sério equivale a compreender seu funcionamento e respeitar seus limites - o jogador que não leva o jogo a sério é um péssimo jogador, seja como companheiro, seja como adversário. Nesse sentido, não se joga com a linguagem, assim como não se joga com a compreensão, elas é que jogam conosco (GADAMER, 1997, p. 174 et seq.). 


\section{REFERÊNCIAS}

AGAMBEN, Giorgio. Infância e história: destruição da experiência e origem da história. Tradução Henrique Burigo. Belo Horizonte: UFMG, 2005.

BARROS, José D'Assunção Barros. Teoria da história II: os primeiros paradigmas; positivismo e historicismo. Petrópolis: Vozes, 2001.

BENATTE, Antonio Paulo. História, ciência, escritura e política. In: RAGO, Margareth; GIMENES, Renato Aloizio de Oliveira (Org.). Narrar o passado, repensar a história. Campinas: UNICAMP, 2014. p. 61-102.

BENJAMIN, Walter. Magia e técnica, arte e política: ensaios sobre literatura e crítica cultural. Tradução Sergio Paulo Rouanet. São Paulo: Brasiliense, 1994.

BONAVIDES, Paulo; ANDRADE, Paes de. História constitucional do Brasil. 3. ed. Rio de Janeiro: Paz e Terra, 1991.

BONAVIDES, Paulo. Teoria constitucional da democracia participativa. São Paulo: Malheiros, 2001.

BOYD WHITE, James. The Legal imagination. Chicago: University of Chicago Press, 1973.

BRUNER, Jerome. Fabricando histórias: direito, literatura, vida. Tradução Fernando Cássio. São Paulo: Letra e voz, 2014.

BURKE, Peter. A história dos acontecimentos e o renascimento da narrativa. In: BURKE, Peter (Org.). A escrita da história: novas perspectivas. 2. ed. São Paulo: UNESP, 1992. p. 327-348.

CANDIDO, Antonio. O direito à literatura. In: CANDIDO, Antonio. Vários escritos. 5. ed. Rio de Janeiro: Ouro sobre azul, 2011. p. 171-193.

CÁRCOVA, Carlos María. Derecho y narración. In: TRINDADE, André Karam; GUBERT, Roberta. Magalhães; COPETTI NETO, Alfredo (Org.). Direito \& literatura: ensaios críticos. Porto Alegre: Livraria do Advogado, 2008. p. 11-20.

CHALHOUB, Sidney. Machado de Assis, historiador. São Paulo: Companhia das Letras, 2003.

COMPARATO, Fábio Konder. Réquiem para uma Constituição. Revista Trimestral de Direito Público, São Paulo, n. 20, p. 5-11, 1997.

COVER, Robert M. Nomos e narrativa. Anamorphosis - Revista Internacional de Direito e Literatura, v. 2, n. 2, p. 187-268, jul./dez. 2016. doi:10.2307/1340787.

CUNHA, Paulo Ferreira da. Cultura constitucional \& revisões constitucionais. International Studies on Law and Education, v. 30, n. 8, p. 5-16, maio/ago. 2011. 
DWORKIN, Ronald. O império do direito. Tradução Jefferson Luiz Camargo. São Paulo: Martins Fontes, 1999.

. Uma questão de princípio. Tradução Luis Carlos Borges. São Paulo: Martins Fontes, 2000.

EAGLETON, Terry. Teoria da literatura: uma introdução. Tradução Waltensir Dutra. 6. ed. São Paulo: Martins Fontes, 2006.

FAORO, Raimundo. Machado de Assis: a pirâmide e o trapézio. 2. ed. São Paulo: Ed. Nacional, 1976.

FREIRE, Felisbelo. História Constitucional da República dos Estados Unidos do Brasil. Rio de Janeiro: Typographia Aldina, 1894.

FREYRE, Gilberto. Casa-grande \& senzala. 50. ed. São Paulo: Global, 2005.

GADAMER, Hans-Georg. Estética y hermenéutica. Tradução José Francisco Zúñiga García. Revista de Filosofía - Facultad de Filosofía y Letras, v. 3. n. 12, p. 5-10, 1996.

. Verdade e método: traços fundamentais de uma hermenêutica filosófica. Tradução de Flávio Paulo Meurer. Petrópolis: Vozes, 1997. v. 1.

. Verdade e método: complementos e índice. Tradução Ênio Paulo Giachini. Petrópolis: Vozes, 2002. v. 2.

GLEDSON, John. Machado de Assis: ficção e história. Tradução de Sonia Coutinho. 2. ed. São Paulo: Paz e Terra, 2003.

GONZÁlEZ, José Calvo. Direito curvo. Tradução André Karam Trindade, Luis Rosenfield, Dino del Pino. Porto Alegre: Livraria do Advogado, 2013.

GOTTSCHALK, Louis. Understanding history: a primer of historical method. New York: Knopf, 1969.

HABERLE, Peter. Hermenêutica constitucional: a sociedade aberta dos intérpretes da constituição; contribuição para interpretação pluralista e procedimental da Constituição. Tradução de Gilmar Ferreira Mendes. Porto Alegre: Sergio Antonio Fabris Editor, 1997.

HARLAN, David. A História Intelectual e o Retorno da Literatura In: RAGO, Margareth; GIMENES, Renato Aloizio de Oliveira (Org.). Narrar o passado, repensar a história. Campinas: UNICAMP, 2014. p. 13-60.

HAYDEN WHITE. Metahistoria: La imaginación histórica em la Europa del siglo XIX. Traducción de Stella Mastrangelo. México: Fondo de Cultura Económica, 1992.

HAYDEN WHITE. El texto histórico como artefacto literario y otros escritos. Traducción e introducción Verónica Tozzi. Barcelona: Ediciones Paidós, 2003.

HUTCHEON, Linda. A poética do pós-modernismo. Rio de Janeiro: Imago, 1991. 
KARAM, Henriete. $O$ direito na contramão da literatura: a criação no paradigma contemporâneo. Revista Eletrônica do Curso de Direito da UFSM, Santa Maria, RS, v. 12, n. 3, p. 1022-1043, dez. 2017. doi: 10.5902/1981369429566.

LANGLOIS, V.; SEIGNOBOS, Ch. Introdução aos estudos históricos. Tradução de Laerte de Almeida Moraes. São Paulo: Renascença, 1946.

LUKÁCS, György. O romance histórico. São Paulo: Boitempo, 2011.

MARTINS, Estevão de Rezende. Conhecimento histórico e historiografia brasileira contemporânea. Revista Portuguesa de História, Coimbra, v. 42, p. 197-217, 2011.

OLIVEIRA, Marcelo Andrade Cattoni de. Direito constitucional. Belo Horizonte: Mandamentos, 2002.

OST, François. Contar a lei: as fontes do imaginário jurídico. São Leopoldo: Unisinos, 2004. PESAVENTO, Sandra. Apresentação. In: PESAVENTO, Sandra (Org.). Leituras cruzadas: diálogos da história com a literatura. Porto Alegre: Ed. da UFRGS, 2000. p. 7-8.

. História \& literatura: uma velha-nova história. In: COSTA, Cléria Botelho da; MACHADO, Maria Clara Tomas (Org.). História \& literatura: identidades e fronteiras. Uberlândia: Edufo, 2006. p. 11-27.

RESTA, Eligio. Código narrativo. Tradução Dino del Pino. In: TRINDADE, André Karam; GUBERT, Roberta Magalhães; COPETTI NETO, Alfredo (Org.). Direito \& literatura: ensaios críticos. Porto Alegre: Livraria do Advogado, 2008. p. 39-59.

RICOEUR, Paul. Histoire et verité. Paris: Seuil, 2001.

SALDANHA, Nelson. Ordem e hermenêutica. 2. ed. Rio de Janeiro: Renovar, 2003.

SCHWARTZ, Germano. A Constituição, a literatura e o direito. Porto Alegre: Livraria do Advogado, 2006.

SILVA NETO, Manoel Jorge e. Constitucionalismo brasileiro tardio. Brasília: ESMPU, 2015.

STEIN, Ernildo. Gadamer e a consumação hermenêutica. Problemata - Revista Internacional de Filosofia, v. 5, n. 1, p. 204-226, 2014.

STRECK, Lenio. Jurisdição constitucional e hermenêutica: uma nova crítica do Direito. Porto Alegre: Livraria do Advogado, 2002.

. Verdade e consenso: constituição, hermenêutica e teorias discursivas. 5. ed. São Paulo: Saraiva, 2014.

. Constitucionalismo contemporâneo. In: STRECK, Lenio. Dicionário de hermenêutica: quarenta temas fundamentais da teoria do direito à luz da crítica hermenêutica do Direito. Belo Horizonte: Letramento, 2017. p. 37-39. 
TRINDADE, André Karam; GUBERT, Roberta Magalhães. Direito e literatura: aproximações e perspectivas para se repensar o direito. In: TRINDADE, André Karam; GUBERT, Roberta Magalhães; COPETTI NETO, Alfredo. Direito e literatura: reflexões teóricas. Porto Alegre: Livraria do Advogado, 2008. p. 11-68.

TRINDADE, André Karam. A teoria do direito após Auschwitz: notas a partir de "O leitor”, de B. Schlink. In: TRINDADE, André Karam; GUBERT, Roberta Magalhães; COPETTI NETO, Alfredo (Org.). Direito \& literatura: discurso, imaginário e normatividade. Porto Alegre: Núria Fabris, 2010. p. 27-100.

VESPAZIANI, Alberto. O poder da linguagem e as narrativas processuais. Anamorphosis - Revista Internacional de Direito e Literatura, v. 1, n. 1, p. 69-84, 2015. doi: 10.21119/ anamps.11.69-84

WARAT, Luis Alberto. A ciência jurídica e seus dois maridos. Santa Cruz do Sul: Faculdades Integradas da Santa Cruz do Sul, 1985.

WARD, Ian. Law and Literature: possibilities and perspectives. Cambridge: Cambridge University Press, 1995.

WEISBERG, Richard. The Failure of the World. New Haven: Yale University Press, 1984.

WEST, Robin. Economic man and literary woman: one contrast. Mercer Law Review Georgetown Public Law Research Paper, v. 39. n. 11-52, p. 867-878, 1988.

ZIZEK, Slavoj. A visão em paralaxe. Tradução Maria Beatriz de Medina. São Paulo: Boitempo, 2008. 